\title{
PAI-1 induces cell detachment, downregulates nucleophosmin (B23) and fortilin (TCTP) in LnCAP prostate cancer cells
}

\author{
JERZY JANKUN ${ }^{1,2,3}$, ANSARI M. ALEEM ${ }^{1 *}$, ZOFIA SPECHT ${ }^{1,3 *}$, RICK W. KECK ${ }^{1}$, \\ WIESLAWA LYSIAK-SZYDLOWSKA ${ }^{3}$, STEVEN H. SELMAN ${ }^{1,2}$ and EWA SKRZYPCZAK-JANKUN ${ }^{1}$
}

${ }^{1}$ Department of Urology, Urology Research Center, ${ }^{2}$ Physiology, Pharmacology, Metabolism, and Cardiovascular Sciences, Health Science Campus, University of Toledo, Toledo, OH, USA; ${ }^{3}$ Department of Clinical Nutrition, Institute of Internal Medicine, Medical University of Gdansk, Poland

Received March 2, 2007; Accepted April 2, 2007

\begin{abstract}
Plasminogen activator inhibitor (PAI-1) is an anticancer agent that inhibits plasmin driven proteolysis, limiting angiogenesis and metastasis. In low concentrations it could induce cancer cell motility by interacting with urokinase (uPA), its receptor (uPAR), vitronectin and integrins. Active PAI-1 binds to uPA forming a complex with uPAR, while the latent form of PAI-1 does not. PAI-1 is found in both forms in the circulation. It is not clear which form acts as an anticancer agent and how it interacts with malignant cells. To investigate how these forms reduce angiogenesis or metastasis, we have created PAI-1 cysteine mutants in the active conformation (VLHL PAI-1) with an extended half-life that reaches $\sim 700 \mathrm{~h}$ and its R369A mutant, which has an active conformation but cannot bind to uPA (VLHL ${ }_{\mathrm{NS}}$ PAI-1). Both VLHL PAI-1s convert into the latent form when treated with a reducing agent (DTT) that breaks disulfide bridges. Unexpectedly, during routine investigation of LnCAP cell proliferation, we have found that cells detach from the culture vessels regardless of PAI-1 conformation or activity. Further investigation showed that treatment of cancer cells with VLHL PAI-1 downregulated nucleophosmin, while all forms of PAI-1 downregulated fortilin. These two proteins are implicated in important cellular processes (cell growth, cell cycle, malignant transformation). This suggests that PAI-1, in addition to its well-known anticancer properties, plays an important role in cell signaling. We hope that by exploring PAI-1's structure and function we might be able to understand and separate the different effects of PAI-1 on cancer cells and develop more effective therapeutic strategies in cancer treatment.
\end{abstract}

Correspondence to: Dr Jerzy Jankun, Urology Research Center, University of Toledo, Health Science Campus, 3065 Arlington, Toledo, OH 43614-5807, USA

E-mail: jerzy.jankun@utoledo.edu

${ }^{*}$ Contributed equally

Key words: plasminogen activator inhibitor, cancer, nucleophosmin, fortilin, cell detachment

\section{Introduction}

During carcinogenesis, malignant cells with abnormally high proteolytic activity degrade extracellular matrix proteins facilitating invasion and metastasis. In cancer-related angiogenesis, proteolytic activity is high at the tip of the capillary vessels, which allows the formation of a dense network of neovasculature in the proximity of the tumor mass to support cancer growth $(1,2)$. Consequently, inhibition of proteolysis has been explored as a therapeutic option to limit invasion, metastasis and angiogenesis (3-5). Most of the attention has been concentrated on the inhibition of metalloproteinases and some of their inhibitors are in clinical studies (6-8). Much less consideration has been paid to inhibition of enzymes leading to plasmin formation. Such inhibitors have shown also strong anticancer activity in preclinical studies (9-11).

Plasmin is able to hydrolyze many extracellular proteins, either directly or through the activation of other matrixdegrading proteases. The plasminogen activation cascade contains several enzymes that control the generation of plasmin. Plasmin is produced from its abundant zymogen (plasminogen) by the plasminogen activators, urokinase plasminogen activator (6) and tissue plasminogen activator (tPA). Physiologically required plasmin activity can be controlled either directly by the inactivation of plasmin by antiplasmin or indirectly by plasminogen activator inhibitors (12). Several studies, including our own, have shown that inhibitors of UPA prevent plasmin formation and consequently limit cancer growth by blocking angiogenesis $(4,13,14)$.

Two different methods of uPA inhibition are evident: 1 ) by small molecular inhibitors and 2) by plasminogen activator inhibitor. The first one is limited by a lack of specificity. These inhibitors bind to the specificity pocket that is highly conserved among serine proteases and consequently many uPA inhibitors bind to other enzymes as well. Plasminogen activator inhibitor type one (PAI-1) is more selective. However, this non-immunizing and highly specific uPA inhibitor is not a stable molecule and converts itself into the latent form with a half-life of $t_{1 / 2}=1-2 \mathrm{~h}$. This conversion is associated with partial insertion of the reactive loop (P4-P10') into the PAI-1 molecule. In this conformation, P1-P1' and other sites are not accessible for reaction with uPA and latent PAI-1 is 
not suitable for anticancer therapy. Several mutants have been produced to reduce or prevent insertion of the reactive loop into the PAI-1 molecule, extending its half-life from 2 to 6$168 \mathrm{~h}(15,16)$. We have produced several different PAI-1 mutants by replacing selected amino acids with cysteines in the goal of creating disulfide bridges, which could prevent insertion or make it more difficult. This has resulted in proteins with extended half-lives of serpin activity from 2 to over $700 \mathrm{~h}$, depending on the mutant (9).

The literature on PAI-1 in cancer and angiogenesis reflects its potential for diverse biologic activity. There are reports that PAI-1 overexpression is a strong prognostic marker in many malignances (17). This fact and experiments done on a PAI-1 knockout and transgenic mice lead to the conclusion that PAI-1 is needed for cancer progression and malignantassociated angiogenesis $(18,19)$. However, Dellas and Loskutoff report that the effect of PAI-1 on cancer depends largely on PAI-1 concentration. In low concentrations, PAI-1 is proangiogenic and procarcinogenic, but in high concentrations, it prevents angiogenesis and reduces tumor size in PAI-1treated animals (19). Our own study has shown similar effects (4).

It is not completely clear what roles the active and latent forms of PAI-1 play in vivo. For example, it has been reported that all active PAI- 1 in the circulation is bound to vitronectin, which stabilizes it, while the majority of PAI-1 in human platelets is in the latent form $(4,20,21)$. Dellas and Loskutoff caution that PAI-1 exerts a broad spectrum of effects in tumor biology from the inhibition of uPA-induced proteolysis to effects on cell migration and angiogenesis, which might or might not be necessarily related to PAI-1 serine protease inactivation ability (19).

Thus, in attempt to explain the mechanism of PAI-1 action on cancer formation, we have used VLHL PAI-1 with a very long half-life and its newly created mutant VLHL $_{\mathrm{NS}}$ PAI-1) that does not bind to uPA but has an extended loop like VLHL PAI-1. In a series of experiments, LnCAP cells were treated with these different forms of PAI-1 and unexpectedly we found that PAI-1 caused detachment of cells from the surface of culture vessels, followed by aggregation of these cells. This effect was observed for wildtype PAI-1, VLHL PAI-1 that binds UPA and its non-uPA binding mutant and all VLHL PAI-1s converted to the latent form. Further, we have found that VLHL PAI-1 treatment downregulated several proteins and that some of them (NPM, nucleophosmin and TCTP, fortilin) are implicated in important cellular processes, such as cell growth, cell cycle progression and malignant transformation $(22,23)$. These findings suggest that PAI-1, in addition to its well-known anticancer abilities based on its anti-uPA activity, possesses additional properties in cell signaling.

\section{Materials and methods}

Molecular graphics. SwissPDB, Chain version 7 and PyMOL viewers were used to display the three-dimensional structures of proteins and to generate POV-Ray scenes $(24,25)$. Protein alignment was done using the program ALIGN (26).

Recombinant PAI-1 with a very long half-life (VLHL). The mutation of two amino acids (Gln197 $\rightarrow$ Cys, Gly355 $\rightarrow$ Cys) produced PAI-1 with a very long half-life of over $700 \mathrm{~h}$ as described by us before (9). The VLHL $\mathrm{NS}_{\mathrm{NS}}$ PAI-1 mutation (Arg369 $\rightarrow$ Ala) was introduced by PCR. We have assumed that the $\mathrm{VLHL}_{\mathrm{NS}}$ construct would remain in the active conformation like VLHL PAI-1, but would not have any inhibitory activity toward uPA. Each PAI-1 DNA construct was sequenced to confirm mutations by MWG-Biotech Inc., Mendenhall Oaks Parkway, NC 27265.

Purification of PAI-1s. We used a baculovirus expression system basically as described before (27). The supernatant from lysed cells was loaded onto a column packed with nickel resin (Invitrogen) at a flow rate of $0.3 \mathrm{ml} / \mathrm{min}$ (GradiFrac System, Pharmacia Biotech). The column was then washed with wash buffer containing $40 \mathrm{mM}$ imidazole in native buffer at a flow rate of $1 \mathrm{ml} / \mathrm{min}$ until no proteins were detected. The protein was then eluted from the column using a gradient of $40-250 \mathrm{mM}$ imidazole in native buffer at a flow rate of $1 \mathrm{ml} /$ min. The peak fractions were dialyzed to remove imidazole and concentrated to a desired concentration for further analysis.

Non-reducing gel electrophoresis. The electrophoresis was performed at room temperature in gradient gels with 4-12\% polyacrylamide, in the absence of $\beta$-mercaptoethanol. All gels were scanned, converted to black and white images, for which contrast and/or brightness were adjusted if needed. The following molecular weight standards were used: 191, $97,64,51,39,28,19$ and $14 \mathrm{kDa}$.

2D gel electrophoresis. The control and treated cells were harvested, washed five times in wash buffer $(10 \mathrm{mM}$ Tris- $\mathrm{HCl}$ and $5 \mathrm{mM}$ magnesium acetate) and suspended in lysis buffer [8 M urea, $2 \mathrm{M}$ thiourea, 4\% chaps, $65 \mathrm{mM}$ DTT, $40 \mathrm{mM}$ Tris, 1\% IPG buffer ( $\mathrm{pH}$ 4.0-7.0, Amersham Biosciences)] on ice for $10 \mathrm{~min}$, followed by sonication, centrifugation at $21,000 \mathrm{x} g$ for $15 \mathrm{~min}$. Supernatant was collected and protein concentration was measured by Bradford method (28). Five hundred $\mu \mathrm{g}$ of each sample in $350 \mu \mathrm{l}$ was used to rehydrate the $18 \mathrm{~cm}, \mathrm{pH} 4.0-7.0$ or 3-10 IPG strip (GE Health care) for $18 \mathrm{~h}$. Proteins were focused in an IPG-Phor system with the setting of $500 \mathrm{~V}(\sim 2.5 \mathrm{~h})$ and $3500 \mathrm{~V}(\sim 17 \mathrm{~h})$. Next, strips were equilibrated for $20 \mathrm{~min}$ in equilibration buffer (6 M urea, $1 \%$ SDS, $30 \%$ glycerol, 50 mM Tris-HCl, 32.4 mM DTT, pH 6.8) and then alkylated for $20 \mathrm{~min}$ in equilibration buffer containing $244.5 \mathrm{mM}$ iodoacetamide. The proteins were then separated on $12 \%$ gel using Ettan Dalt Six $(24 \times 20 \mathrm{~cm})$ gel system at $10^{\circ} \mathrm{C}$, constant current $(30 \mathrm{~mA} /$ gel for initial $1 \mathrm{~h}$ followed by $50 \mathrm{~mA} / \mathrm{gel}$ ) until the tracking dye reached the bottom.

Western blot analysis. The PAGE gel was equilibrated in Transfer Buffer-TBS (24\% methanol, 96 mM glycine, $12 \mathrm{mM}$ Tris- $\mathrm{HCl}$ ) for $5 \mathrm{~min}$ and proteins were transferred to a nitrocellulose membrane, washed in Blotting Buffer-TBST (PBS, pH 7.6 and 0.1\% Tween-20), blocked in Blotting Buffer containing $5 \%$ non-fat dry milk for $1.5 \mathrm{~h}$ at $40^{\circ} \mathrm{C}$. The membrane then was treated with rabbit anti-human PAI-1 (American Diagnostica, Inc., Stamford, CT; $2 \mu \mathrm{g} / \mathrm{ml}$ ) overnight in TBST $/$ milk solution at $40^{\circ} \mathrm{C}$. The next morning, the membrane was washed 3 times in TBST for $5 \mathrm{~min}$ at room temperature. The second antibody was added (anti-rabbit IgG Sigma, Inc., in 1:4,000 dilution) in TBST/milk solution for 
$1 \mathrm{~h}$ at room temperature followed by washing (3 times in TBST and once in TBS for $5 \mathrm{~min}$ ).

Spectrozyme $^{\circledR}$ assay of PAI-1 activity. Activity assay of PAI-1 was done as described by the manufacturer (American Diagnostica Inc.) with minor modifications. Briefly, equal volumes $(50 \mu \mathrm{l})$ of VLHL PAI-1 (diluted with $\mathrm{H}_{2} \mathrm{O}$ from the stock of $1.0 \mathrm{mg} / \mathrm{ml}$ in $20 \mathrm{mM}$ HEPES, $250 \mathrm{mM}$ imidazole, pH 8.0 to a concentration $0.06 \mathrm{mg} / \mathrm{ml}$ ) and HMW uPA from American Diagnostica Inc. (0.3 mg/ml in water) were mixed and incubated for $15 \mathrm{~min}$ at room temperature, followed by the addition of $50 \mu \mathrm{l}$ of the chromogenic substrate of uPA (Spectrozyme uPA ${ }^{\circledR}$ American Diagnostica Inc., final concentration of $1.7 \mathrm{mM}$ ). The absorbance was measured at $405 \mathrm{~nm}$ in a 96-well plate reader. Urokinase alone and wtPAI-1/uPA were used as controls.

PAI-1/uPA complex formation assay. PAI-1 and uPA mixed as described above and incubated for $15 \mathrm{~min}$ were run on a PAGE gel and stained.

Staining of free -SH with fluorescent dye. The purified VLHL

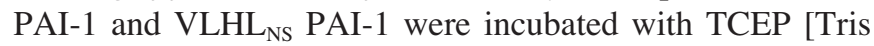
(2-carboxyethyl) phosphine] up to a final concentration of $65 \mathrm{mM}$ for $2 \mathrm{~h}$ at room temperature, followed by staining with 5-IAF dye (from Molecular Probes) at a final concentration of $1 \mathrm{mM}$ for $2 \mathrm{~h}$ in the dark. This dye binds to $-\mathrm{SH}$ thiols but not to disulfide bridges of the VLHL PAI-1s. All samples were then processed for SDS-PAGE (performed in the dark). Protein bands were visualized under a UV transilluminator, photographed and then the same gel was stained with Coomassie blue.

In-gel digestion with trypsin. The proteins stained with Coomassie blue was excised from the $4-12 \%$ gradient SDSPAGE gel and destained later with $30 \%$ methanol for $3 \mathrm{~h}$ at room temperature. In-gel proteolysis with modified, sequencing grade trypsin (Promega, Madison, WI) was done essentially as previously described (29).

PAI-1 and PAI-1/uPA complex identification by peptide sequencing using liquid chromatography-tandem mass spectrometer $(L C-M S)$. The digest $(2 \mu 1)$ was separated on a reverse phase column (Aquasil C18, $15 \mu \mathrm{m}$ tip x $75 \mu \mathrm{m}$ i.d. x $5 \mathrm{~cm}$ Picofrit column, New Objectives, Woburn, MA) using an acetonitrile/1\% acetic acid gradient system (5-75\% acetonitrile over $35 \mathrm{~min}$ followed by $95 \%$ acetonitrile wash for $5 \mathrm{~min}$ ) at a flow rate of $250 \mathrm{nl} / \mathrm{min}$. Peptides were directly introduced into an ion-trap mass spectrometer (LCQ, ThermoFinnigan) equipped with a nano-spray source. The mass spectrometer was set for analyzing the positive ions and acquiring a full MS scan of a collision induced dissociation spectrum on the most abundant ion from the full MS scan (relative collision energy $30 \%$ ). Dynamic exclusion was set to collect 3 CID spectra on the most abundant ion and then exclude it for $2 \mathrm{~min}$. CID spectra were manually verified by comparison with an in silico tryptic digest of published protein sequences using the MS-Digest and MS-Product provisions of Protein Prospector (http://prospector.ucsf.edu). All LC-MS experiments were done at Proteomics Laboratory, Program in
Bioinformatics and Proteomics/Genomics at the Health Science Campus of the University of Toledo.

Cell culture. Cells (LnCAP) were seeded in T25 or T75 flasks in MEM media with 10\% FBS and antibiotics and incubated until the cells reached $\sim 70 \%$ confluence. Cells were treated in fresh media with different concentrations of PAI-1 (final concentrations in media: $1,10,50,100 \mu \mathrm{g} / \mathrm{ml}$ ) or an irrelevant protein.

Cell proliferation assay. Prostate cancer cells were seeded at a density of $5 \times 10^{4}$ cells/well in MEM media with $10 \%$ FBS and antibiotics and incubated (96-well cell culture plate) until the cells reached $\sim 70 \%$ confluence. LnCAP cells were treated for up to $72 \mathrm{~h}$ with different concentrations of PAI-1 (final concentrations in media: $1,10,50,100 \mu \mathrm{g} / \mathrm{ml}$ ) or an irrelevant protein or appropriate buffer in control samples. After treatment, the number of viable cells was determined using Promega's CellTiter 96 AQueous MTS Assay according to the manufacturer's instructions. Cell proliferation was determined as a fraction of the control sample and measured as absorbance at $540 \mathrm{~nm}$. Each concentration or control results represent an average of 6 to 16 wells.

Cell viability. Viability of the cells was determined by trypan blue exclusion method.

Removal of cell surface associated proteins. An acid wash was done in a similar way as described before (30). Cells were treated with $3 \mathrm{ml}$ of $50 \mathrm{mM}$ glycine- $\mathrm{HCl}, 0.1 \mathrm{M} \mathrm{NaCl}, \mathrm{pH} 3.0$. Acid wash was quickly neutralized with $0.9 \mathrm{ml}$ of $0.5 \mathrm{M}$ Tris$\mathrm{HCl}, \mathrm{pH}$ 7.8. The samples were concentrated using Vivaspin 20 concentrators $(10,000$ MWCO from Vivascience Company, Inc.) to final concentration of total protein ranged from 1.0 to $2.6 \mathrm{mg} / \mathrm{ml}$.

\section{Results and Discussion}

Protein purification. We have extensively studied mutations of PAI-1 to extend PAI-1 half-life by the introduction of Cys mutations as described in our previous report (9). As shown in Fig. 1, we assume that cysteines form bridges between A3 and A5 strands, preventing collapse of the reactive loop into the PAI-1 molecule and consequently preclude conversion of the active form to the latent form. One of these mutants has half-life of over $700 \mathrm{~h}$ (VLHL PAI-1) in contrast to $2 \mathrm{~h}$ for the wild-type PAI-1 (31). We chose this mutant for further study. To increase the yield, we have expressed VLHL PAI-1 in baculovirus. All VLHL PAI-1s DNA was sequenced, validating PAI-1 sequence with linker, purification tag and desired mutations.

The VLHL PAI-1s yielded $\sim 95 \%$ pure protein $(\sim 18 \mathrm{mg} / \mathrm{l})$ in a single step purification as determined by PAGE gel densitometry (Fig. 2). VLHL PAI-1 was produced in high purity $(+95 \%)$, predominantly in the active conformation.

Urokinase inhibitory activity by VLHL PAI-1s. The active form of VLHL PAI-1 inhibits urokinase activity, as determined by a chromogenic assay with Spectrozyme. The PAI-1 mutant with Arg369 $\rightarrow$ Ala in the P1 position $\left(\mathrm{VLHL}_{\mathrm{NS}} \mathrm{PAI}-1\right)$ shows 

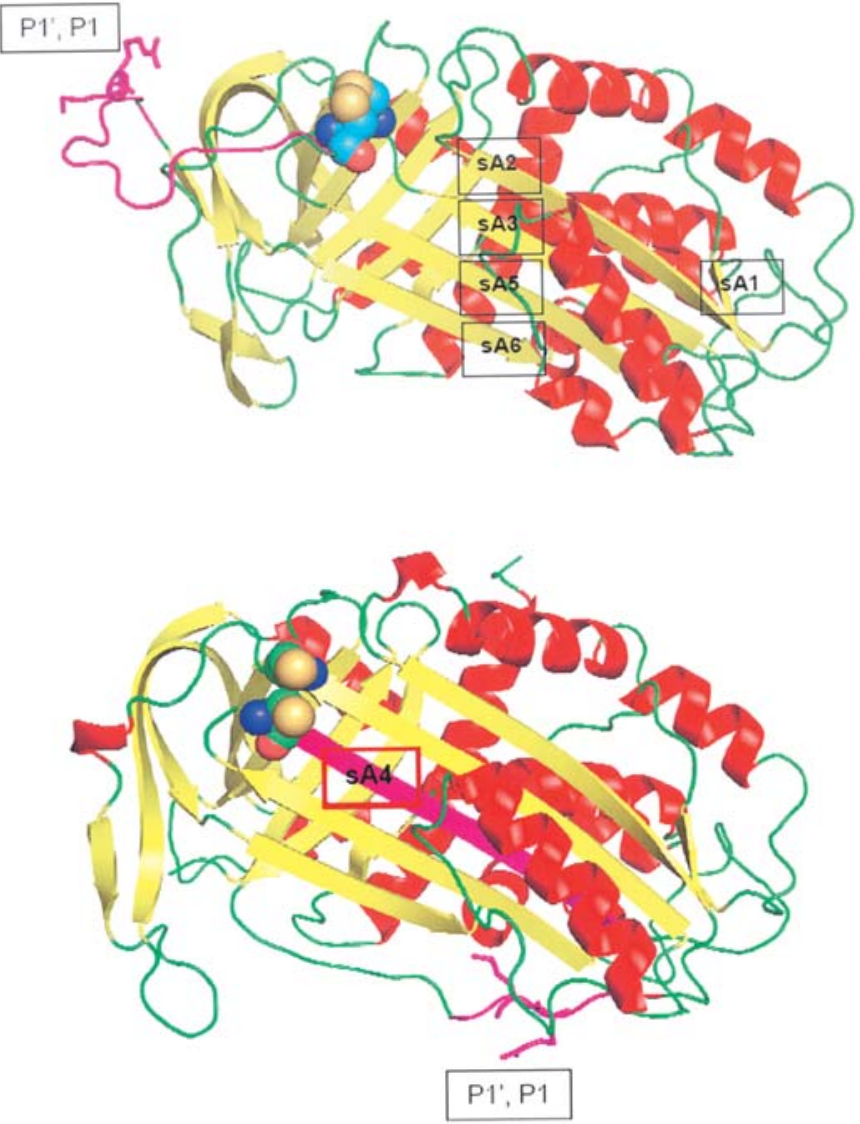

Figure 1. In active conformation PAI-1's (a) reactive center loop (in magenta) is extended from the main body of protein molecule, in latent conformation (b) this loop is inserted between A3 and A5 strands of PAI-1, turning into strand A4 and is not available for reaction with PAI-1 substrates. P1', P1 (Arg369, Met370) of active site as indicated. Cysteines (shown as spheres) were able to form disulfide bridge and to freeze PAI-1 in active conformation. Reduction of the disulfide bridge permits a molecule of VLHL PAI-1 to convert into latent form as wPAI-1 does.

no activity against uPA, which is consistent with previous reports $(15,32)$.

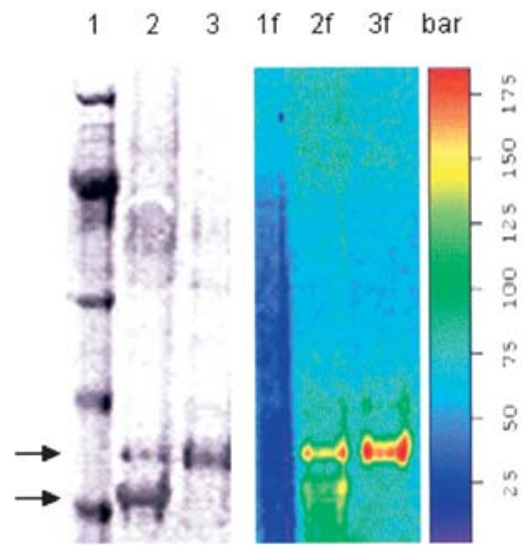

Figure 3. PAGE electrophoresis of: lane 1, molecular weight standards; lane 2, VLHL PAI-1 in active conformation; lane 3, VLHL PAI-1-treated with DTT (in latent conformation); lane f, fluorescence in false color, UV illuminated; lane 1f, molecular weight standards; lane 2f, VLHL PAI-1 in active conformation; lane 3, VLHL PAI-1-treated with TCEP; bar, false color scale.

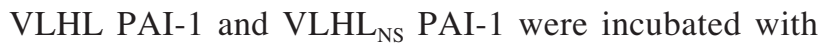
uPA and run on a PAGE gel. Active PAI-1 produces a band of protein of the molecular weight characteristic of PAI-1/

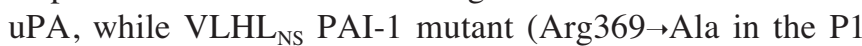
position) does not. The protein band of uPA/VLHL PAI-1 was excised from gel and analyzed by MS-LC (Fig. 2b, Table I). No other peptides than those of PAI-1 and uPA were identified, further confirming the formation of the uPA/PAI-1 complex and VLHL PAI-1 activity.

Under oxidizing conditions when cysteines form disulfide bridges (Cys197 and Cys355), the RCL loop (reactive center loop) is immobilized and cannot be inserted into the PAI-1 molecule (Fig. 1). Consequently, reduction of the disulfide bond by reducing agent should restore A3, A5 and RCL mobility, making conversion of VLHL PAI-1s to the latent form possible. Purified VLHL and VLHL $\mathrm{VL}_{\mathrm{NS}} \mathrm{PAI}-1 \mathrm{~s}$ and wtPAI-1s were treated with DTT (10-65 mM) for up to $3 \mathrm{~h}$.

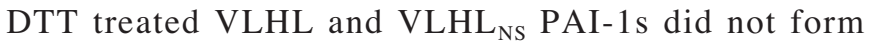
complexes and did not express any uPA inhibitory activity. VLHL and VLHL $_{N S}$ mutants treated with DTT convert into $\mathbf{a}$

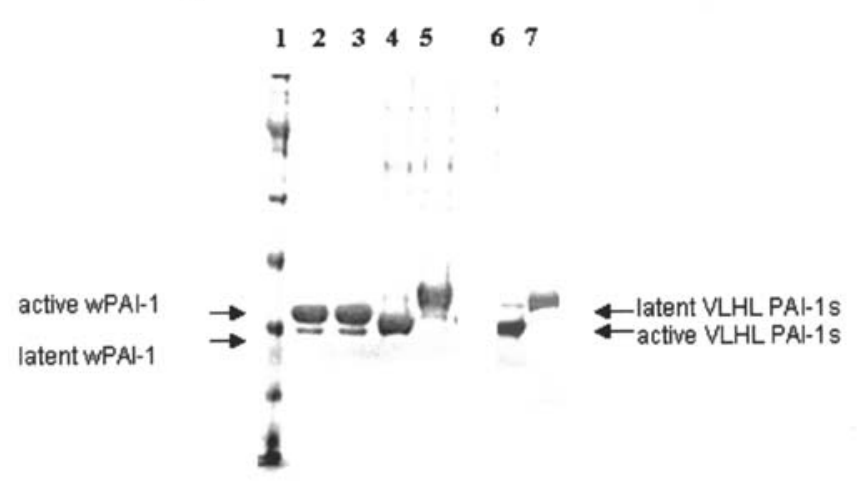

b

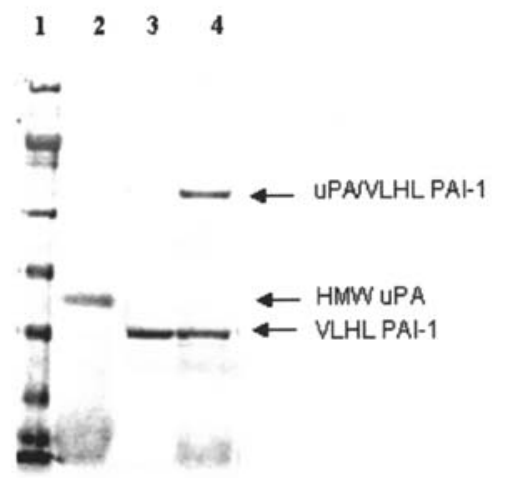

Figure 2. PAGE electrophoresis. Lane 1, molecular weight standards (from the top 191, 97, 64, 51, 39, 28, 19 and 14 kDa); lane 2, wPAI-1; lane 3, wPAI-1-

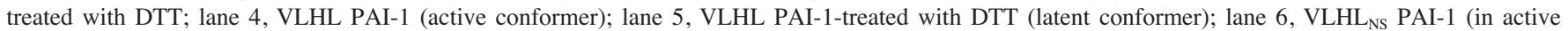
conformation); lane 7, VLHL $\mathrm{NS}_{\mathrm{SAI}}$ 1-treated with DTT (latent conformer, lines 6 and 7 pasted from different gel). b: lane 1, protein standards; lane 2, HMW uPA; lane 3, VLHL PAI-1; lane 4, mixture of uPA and VLHL PAI-1 and complex of uPA with VLHL PAI-1. 
Table I. Sequence of peptides extracted from band of uPA/PAI-1 complex on PAGE gel.

\begin{tabular}{|c|c|c|c|c|c|}
\hline $\begin{array}{l}\text { Protein } \\
\text { accession no. }\end{array}$ & $\begin{array}{l}\text { Protein } \\
\text { names }\end{array}$ & $\begin{array}{c}\text { Theoretical } \\
\text { mass }\end{array}$ & $\begin{array}{l}\text { Observed } \\
\text { mass }\end{array}$ & Peptide & Sequence \\
\hline \multirow[t]{10}{*}{ P05121 } & Plasminogen activator & 1144.53 & 1144.84 & $200-209$ & TPFPDSSTHR \\
\hline & inhibitor type one (PAI-1) & 859.46 & 859.54 & $178-185$ & GAVDQLTR \\
\hline & & 1105.60 & 1105.26 & $42-51$ & VFQQVAQASK \\
\hline & & 1684.75 & 1685.02 & $215-230$ & SDGSTVSVPmmAQTNK \\
\hline & & 1108.52 & 1108.74 & $146-154$ & QVDFSEVER \\
\hline & & 1583.75 & 1583.52 & $311-323$ & KPLENLGmTDmFR \\
\hline & & 948.51 & 948.80 & $169-177$ & GmISNLLGK \\
\hline & & 1494.74 & 1494.92 & $112-124$ & DEISTTDAIFVQR \\
\hline & & 1208.61 & 1208.24 & $301-310$ & FSLETEVDLR \\
\hline & & 1034.56 & 1034.86 & $157-164$ & FIINDWVK \\
\hline \multirow[t]{7}{*}{ P00749 } & Urokinase plasminogen activator & 593.33 & 593.45 & $334-338$ & mTVVK \\
\hline & & 935.49 & 935.14 & $404-411$ & DKPGVYTR \\
\hline & & 1111.59 & 1111.94 & $156-165$ & KPSSPPEELK \\
\hline & & 1198.60 & 1199.80 & $421-431$ & SHTKEENGLAL \\
\hline & & 1001.56 & 1001.16 & $109-118$ & SDALQLGLGK \\
\hline & & 1241.68 & 1241.92 & $254-263$ & FEVENLILHK \\
\hline & & 1047.49 & 1047.94 & $350-358$ & ${ }^{1}$ YYGSEVTTK \\
\hline
\end{tabular}

m, oxidized methionine; ${ }^{1}$ non-tryptic.

the latent form, as wild-type PAI-1 does, and migrate as a single band corresponding to the latent form of VLHL PAI-1 (Figs. 2 and 3).

Also, as shown in Fig. 3, VLHL PAI-1s were stained with a fluorescent dye to determine presence of free thiols in the PAI-1 molecule. VLHL PAI-1 in the active conformation showed no or very little fluorescence, while DTT treated, inactive VLHL PAI-1s in the latent conformation showed a strong signal of 5-IAF (5-iodoacetamidofluorescein) dye bound to the -SH of cysteine. The same was seen for VLHL $\mathrm{NS}_{\mathrm{N}}$ PAI-1. The wild-type PAI-1 purified from HT1080 cells, containing the full sequence of amino acids including Cys9 (the only Cys in this protein), showed strong florescence in both active and latent forms (data not shown). VLHL PAI-1s do not have this cysteine since the first 23 amino acids are truncated from the protein sequence.

It has been reported that wild-type PAI-1 in the active form migrates on PAGE gel as the upper band and the latent and RCC (cleaved reactive center loop) forms migrate below it $(33,34)$. However, PAI-1 with cysteine mutations that form disulfide bonds migrates below its latent or RCC forms, which is completely contrary to the wild-type form of PAI-1 (Figs. 2 and 3). This phenomenon was reported by others (35). The exact mechanism is unknown, but Hagglof et al hypothesized that in PAI-1s with Cys mutations in the A3 and A5 strands, the reactive loop that forms a bulge on the left side of PAI-1 (when facing this protein) is shifted to the right side resulting in a more spherical molecule that moves easier through the gel.
From these experiments, we conclude that the disulfide bridge (Cys 197, 355) freezes VLHL PAI-1s in the active conformation and VLHL PAI-1 and VLHL ${ }_{\mathrm{NS}}$ PAI-1 are most likely in the same conformation despite one point mutation (R369A) that causes their differences in uPA inactivation.

Treatment of human prostate cancer cells by VLHL PAI-1s. Our initial experiment was intended to determine the effects of PAI-1 treatment on prostate cancer cells. This experiment was planned as a control for the future determination of PAI-1 effects on angiogenesis in animals. We anticipated no effects on cell proliferation or morphology.

Four different forms of VLHL PAI-1 were used: VLHL

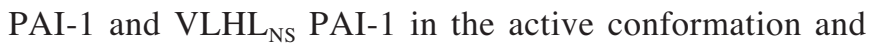
treated with DTT, which converted VLHL PAI-1s to the inactive conformer (DTT was removed by dialysis after treatment). As controls, appropriate buffer, hp-12-LOX as an inert protein and non-treated cells were used.

All PAI-1-treated cells as early as $0.5-1 \mathrm{~h}$ after addition of VLHL PAI-1s start to detach from the surface of 96-well plates in the highest concentration. Later they start to aggregate, producing aggregates of several cells to several thousand cells in one cluster. The ones shown in Fig. 4 have different appearances but all forms were observed in wells treated with different forms of VLHL PAI-1s. In subsequent experiments, we determined that detachment of cells and aggregation can be observed in concentrations of PAI-1s at or higher than $50 \mu \mathrm{g} / \mathrm{ml}$ of media. However, the morphology of the treated 


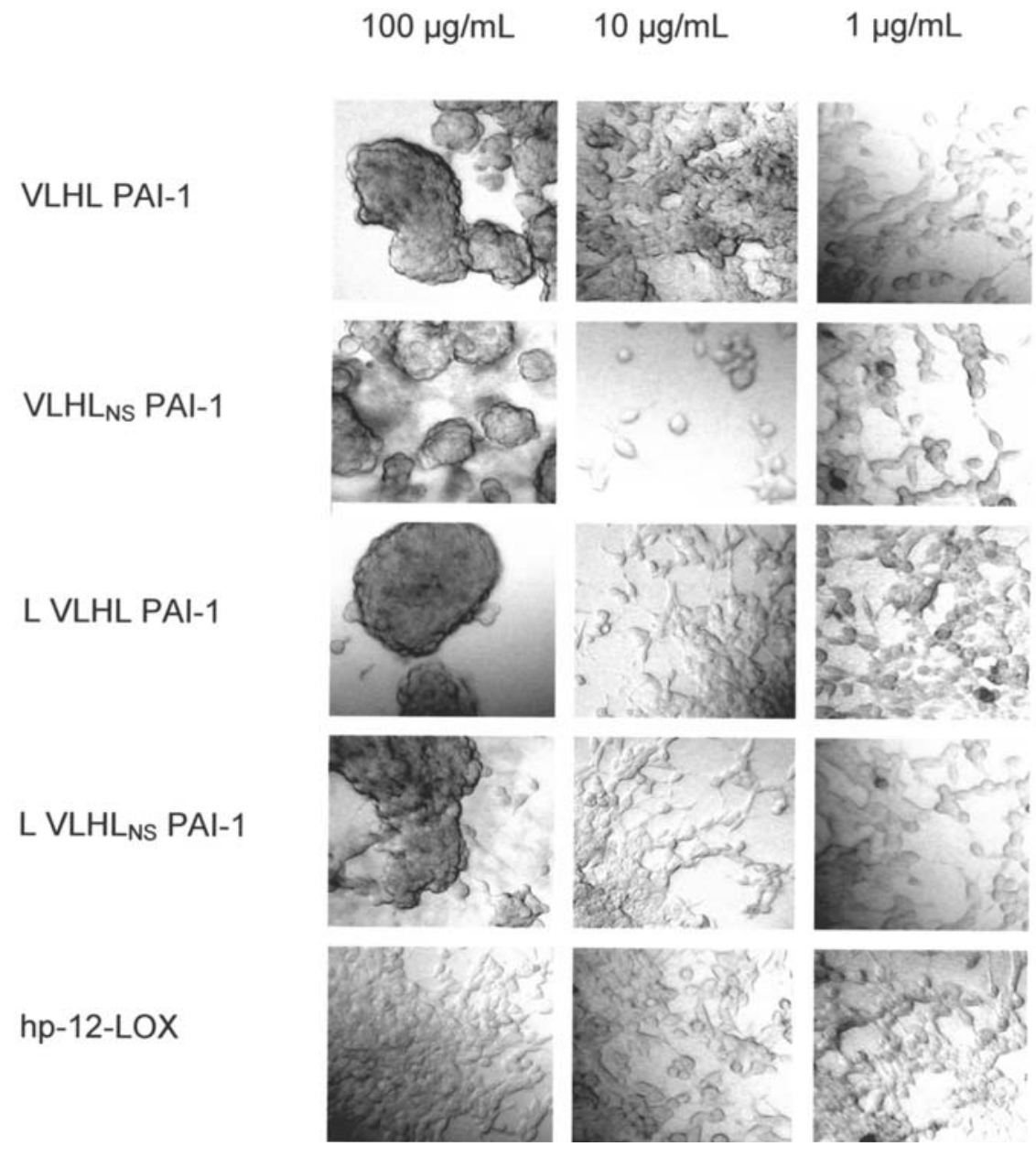

Figure 4. LnCAP cells treated with VLHL PAI-1s in different conformation and in different concentrations in comparison with control. No differences were seen between non-treated cells and treated with buffer only and inert protein.

cells was altered below that value. Promega's CellTiter assay showed a reduction of cell proliferation reaching $73 \%$

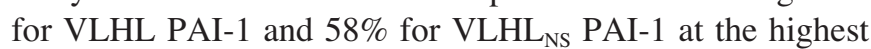
concentration. Also, inhibition of cell proliferation was concentration dependent but at lower concentrations, the data were not statistically significant. Different forms of VLHL PAI-1s also reduced cell viability as is shown in Table II; at the highest concentration, only $\sim 80 \%$ of cells were viable. It is not completely clear if lower proliferation and lower viability of cells was a direct result of PAI-1 presence or a consequence of reduced nutrient uptake by cells detached from flask surface and later aggregated in large clusters.

These effects of PAI- 1 on cells have a very limited representation in the literature. Firstly, Balsara et al reported recently that regulation of endothelial cell proliferation by PAI-1 is dependent on interaction with low-density lipoprotein receptor-related protein (LRP). They also reported that PAI-1 is a negative regulator of cell growth, exerting its effect on the phosphatidylinositol 3-kinase/Akt pathway (36). Secondly, Czekay et al reported that detachment of HT-1080 cells treated with PAI-1 and a PAI-1 mutant did not bind vitronectin. Detachment was observed at a concentration of PAI-1 in a very similar range as in our experiment ( $40 \mu \mathrm{g} / \mathrm{ml}$ and higher). The authors concluded that PAI-1-induced cell detachment requires the presence of UPA-uPAR complexes on the cell surface and depends on the formation of complexes between
Table II. Viability of LnCAP cells treated with different forms of VLHL PAI-1.

$\begin{array}{ll}\text { Cells treated with buffer } & \text { Viability in } \\ \text { or } 100 \mu \mathrm{g} / \mathrm{ml} \text { of PAI-1 } & \text { percentage }\end{array}$

$\begin{array}{ll}\text { Control (buffer vs. non-treated) } & 99.5 \pm 0.4 \\ \text { VLHL PAI-1 } & 87.8 \pm 0.5 \\ \text { VLHL }_{\text {NS }} \text { PAI-1 } & 91.2 \pm 2.5 \\ \text { L VLHL PAI-1 (DTT treated) } & 83.7 \pm 3.8\end{array}$

integrins and the UPAR occupied by uPA (37). Our data possibly indicate a different mechanism. LnCAP cells express very little uPA on the surface. Also, we observed detachment of cells treated with PAI- 1 in the active and latent conformation as well as by uPA binding and non-uPA binding PAI-1s. Furthermore, after detachment we observed cell aggregation that was not reported by Czekay et al. These facts suggest the possibility of an alternative and unknown mechanism of PAI-1 action.

In search of a possible explanation, we have harvested

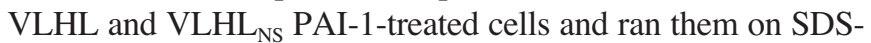




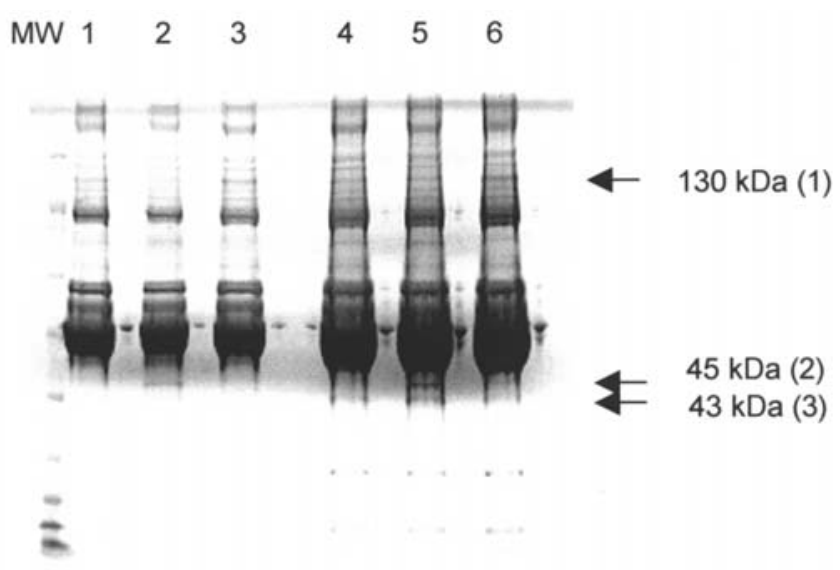

Figure 5. Acidic wash of cells treated with: lane 1, buffer; lane 2, VLHL

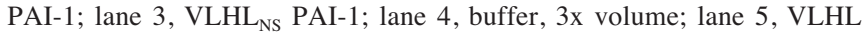
PAI-1, 3x volume; lane 6, VLHL ${ }_{\mathrm{NS}}$ PAI-1, 3x volume; lane MW, molecular weight standards.

PAGE gel followed by Western blot analysis. We expected to detect PAI-1 bound to its ligands (vitronectin, LRP, uPAR, uPA or TPA) and based on molecular weight and future LC-MS we would be able to determine the proteins with which PAI-1 made complexes. On Western blot analysis of control and treated samples, we have observed a thin band at MW $\sim 60 \mathrm{kDa}$. PAI-1 cannot bind to most of the known ligands and migrate in that region. The only ligand that is rarely reported in the literature is $\alpha$-1-acid glycoprotein 2 precursor (38). The combined molecular weight of this protein and PAI-1 could be detected in that region.

To analyze this phenomenon further, all three samples (VLHL, VLHL $_{\mathrm{NS}}$ PAI-1s and control) were run on an SDS gel and the region corresponding to $\sim 60 \pm 10 \mathrm{kDa}$ was excised from the gel and analyzed on LC-MS. Several proteins have been identified, none of which are known PAI-1 ligands or a PAI-1 itself. We have concluded that either the Western blot analysis was detecting non-specific binding or LC-MS was not sensitive enough to detect PAI-1 or PAI-1 complexes.

Acidic wash of cells treated with different PAI-1s. If PAI-1 forms a complex on the surface of LnCAP cells, it should be dissociated from it by an acidic wash. Control and VLHL

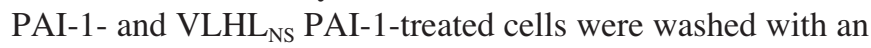
acidic buffer. As shown in Fig. 5, the gel showed a different pattern between control and PAI-1-treated cells. In VLHL PAI-1, we have observed two bands in the $\sim 40 \mathrm{kDa}$ region, while in control and VLHL $_{\mathrm{NS}}$ PAI-1 samples, these bands were in slightly different positions and in lesser amounts (Fig. 5, bands 2 and 3). Based on LC-MS, these two bands contain several proteins, mainly bovine in origin and PAI-1. The signal from PAI-1 was strong; we have identified 5 to 9 peptides in bands 2 and 3 , respectively. These could be endogenously active, latent or VLHL PAI-1s. Unfortunately, none of the 5 to 9 sequences detected contain the Cys mutation that would make this distinction possible. In the case of VLHL $_{\text {NS }}$ PAI-1, these bands were absent and LC-MS did not detect PAI-1 but some other proteins were detected, mostly bovine in origin. This strongly supports the possibility that
LnCAP cells bind active VLHL PAI-1 to the cell surface, most likely through uPA/uPAR and the LRP pathway.

SDS-PAGE of the acid washed cells treated with VLHL $_{N S}$ PAI-1 also showed an additional band at $\sim 130 \mathrm{kDa}$. This band was cut from the gel and analyzed by LC-MS. PAI-1, its ligands or complexes were not detected. All proteins detected were bovine in origin, some most likely dimerized (BSA) and some represented $\mathrm{IgG}$ fragments.

Two dimensional gel electrophoresis of cells treated with different PAI-1s. Since only limited information could be derived from 1D PAGE gels, we analyzed VLHL PAI-1treated LnCAP cells by 2D PAGE. In a few places in the $2 \mathrm{D}$ gel of LnCAP cells treated with VLHL PAI-1, we have detected altered protein spots. Cells treated with other forms of VLHL PAI-1 (inactive mutant or DTT-treated PAI-1 converted into the latent form as well as wtPAI-1 that converts quickly into the latent form) produced virtually the same 2D gels with the exception of one spot. The protein spots are shown in Fig. 6. Several proteins have been identified, but it seems that two of these are of importance in cancer. Both are downregulated; one in VLHL PAI-1-treated cells the other in all PAI-1-treated cells. We have detected nucleophosmin (also known as NPM, nucleolar phosphoprotein B23, numatrin or nucleolar protein NO38) in the typical region for this protein $(\sim 32 \mathrm{kDa})$ but in two different spots, which could be the phosphorylated and unphosphorylated forms of NPM (39). Another downregulated protein was detected in a second area in a much lower molecular weight $(\sim 20 \mathrm{kDa})$. All peptides detected by LC-MS from that region were in the proximity of the $\mathrm{C}$-terminus of the NMP protein, suggesting that a truncated fragment of $\sim 20 \mathrm{kDa}$ contains part of the NPM C-terminus.

NPM is an abundant phosphoprotein that resides in nucleoli, although it shuttles rapidly between the nucleus and cytoplasm. NPM takes part in various cellular processes including the transport of pre-ribosomal particles and ribosome biogenesis, the response to stress stimuli such as UV irradiation and hypoxia and the DNA-repair processes. However, nucleophosmin is also overexpressed in a variety of cancers and it has been proposed as a marker for gastric, colon, ovarian and prostate malignances. The level of its expression has been correlated in some cases with stages of tumor progression (39). It has been implicated that the main biological effects of nucleophosmin overexpression are increased cell growth, proliferation and the inhibition of apoptosis (39). Recent studies by Slupianek et al showed that nucleophosmin/ALK activates phosphatidylinositol 3-kinase (PI3K) and its downstream effector of the serine/threonine kinase (Akt) (40). According to Balsara et al Akt is a key regulator of cell survival events, which targets a number of different cytoplasmic proteins, resulting in inactivation of the proapoptotic pathway (36). In the same study, the authors found that hyperactivation of Akt was observed in proliferating PAI- $1^{-/}$endothelial cells (EC). Also, exogenous PAI-1 diminished the levels of Akt, which is similar to the effect observed by us in the case of NPM. The authors suggested that PAI-1 is a negative regulator of cell growth, exerting its effect on the Akt pathway and that the regulation of proliferation is dependent on its interaction with low-density lipoprotein receptor-related protein. We have not detected 


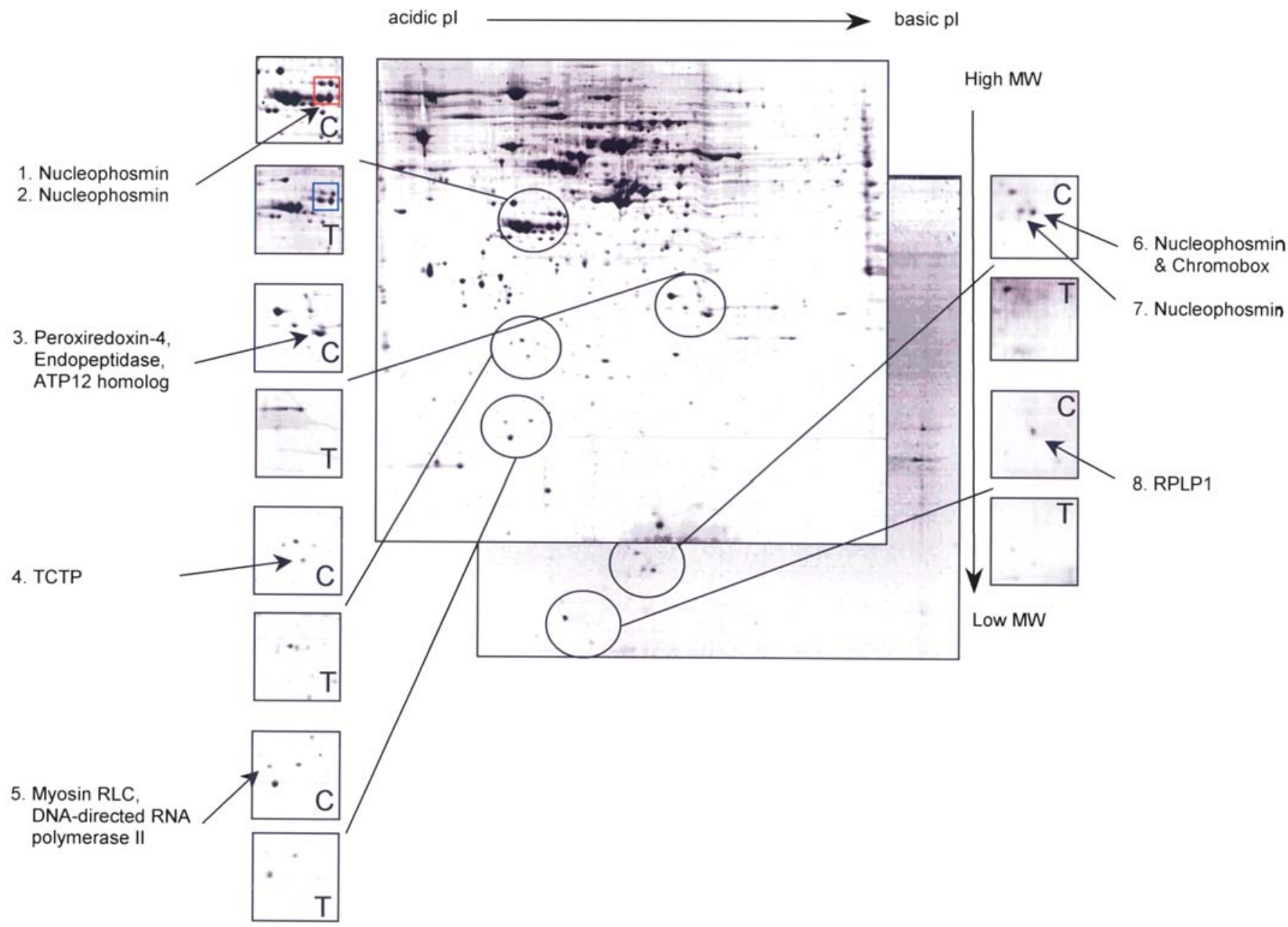

Figure 6. Coomassie blue stained 2D PAGE gels, front - control sample, pI 4-7; gel in background - control sample, pI 3-10. All 'C' inserts represent control sample; ' $\mathrm{T}$ ' inserts showing gels of VLHL PAI-1-treated cells. In some cases we have identified more than one protein as indicated for example in spot 5. Nucleophosmin $(1,2)$ all four spots where analyzed and in case of two lower spots in addition to other proteins we found nucleophosmin in control sample (red square) but not in treated by VLHL PAI-1 (blue square). Other proteins of four spots were identical.

changes in the Akt levels, which might be observed in more detailed studies in the future. However, it is very tempting to speculate that Akt downregulation was the direct result of downregulation of NPM. Indeed, this event can depend on interaction with LRP since changes in NPM levels were observed for PAI-1 that is able to bind to UPA and to form PAI-1/uPA/uPAR/LRP complexes.

The other protein attenuated after PAI-1 treatment and of importance in cancer is translationally-controlled tumor protein (TCTP, also called p23, histamine-releasing factorHRF or fortilin), MW 19.6 kDa species shown in Fig. 6. Contrary to NPM, this protein has been downregulated in all PAI-1-treated cells. TCTP is an anti-apoptotic protein but is not related to the $\mathrm{Bcl}-2$ family of proteins and protein inhibitors of apoptosis. The TCTP message is ubiquitous in normal tissues but especially high in the liver, kidney and small intestine. Also, TCTP is elevated in cancer cells compared to cell lines derived from normal tissue (41).

Tuynder et al described the concept of 'revertants' $(42,43)$. These are cancer cells that were transformed with $\mathrm{v}$-src (so-called flat revertant factor) or chemically-treated, which results in cells with decreased tumor-producing ability. By analyzing the gene expression profile between tumor cells and revertant counterparts, they found a significant downregulation of TCTP in the revertants (41-43). Furthermore, by transecting cancer cells with antisense TCTP, they significantly increased the number of revertant cells (43).

Collectively, these surprising and unexpected observations demonstrate that PAI-1 may affect cells in diverse ways. PAI-1 may act as a negative regulator of cell proliferation and exert its effect on the NPM pathway, as well as in the independent TCTP pathway. The first one is most likely related to the non-proteolytic role of the uPAR/uPA/PAI-1/LRP complex, since both uPAR and LRP have been reported to be involved in cellular signaling pathways (44). The second described event is not related to uPAR/uPA/PAI-1/LRP complex formation as the inactive or latent forms of PAI-1 cannot bind to uPA.

Structural analysis of differences between active and latent conformers of PAI-1. During the conversion from the active to latent form, plasminogen activator inhibitor undergoes a substantial structural rearrangement. Cell detachment and downregulation of TCTP were observed after treatment with PAI-1 regardless of its conformation or serine activity. Thus, we have analyzed differences between the active and latent structures in hope of finding conserved regions of the PAI-1 
molecule responsible for these events. Judging by the RMSD between the two different structures (1B3K, 1C5G), most conserved regions of PAI-1 are helices $(\mathrm{hA}, \mathrm{hB}, \mathrm{hC}, \mathrm{hD}, \mathrm{hE}$, $\mathrm{hH})$ and the loop between strand $\mathrm{s} 1 \mathrm{~B}$ and $\mathrm{s} 2 \mathrm{~B}$. Thus, they constitute the most probable regions of PAI-1 responsible for the detachment of cells and downregulation of TCTP.

In conclusion, our study suggests that the events we have observed after treatment of LnCAP cells with various forms of PAI-1 are driven by independent mechanisms. First, the detachment of cells and their further aggregation and the downregulation of TCTP were unrelated to PAI-1 inhibitory capability or its latent or active conformation. These processes are driven by unknown mechanism(s) and in all probability involve a conserved part of the PAI-1 molecule. Second, downregulation of NPM was associated with active VLHL PAI-1, suggesting a non-proteolytic function of the uPAR/ uPA/PAI-1/LRP complex.

Downregulation of NMP and TCTP by VLHL PAI-1s have not been reported and are novel observations that supplement the known anticancer activity of PAI-1. On the other hand, detachment of cells, which could be related to dissemination of cancer cells in vivo, should be considered a less desired effect of PAI-1. We hope that by altering PAI-1's structure and function we might be able to understand and separate the different effects of PAI-1 on cancer cells and develop more effective therapeutic strategies in cancer treatment.

\section{Acknowledgments}

This work was supported in part by grants from NIH: CA90524, CA109625, and Frank D. Stranahan Endowment Fund for Oncological Research. We thank Dr R. Hart (President of American Diagnostica Inc., Stamford, CT, USA) for his support and the chemicals used in this study.

\section{References}

1. Lah TT, Duran Alonso MB and van Noorden CJ: Antiprotease therapy in cancer: hot or not? Expert Opin Biol Ther 6: 257-279, 2006.

2. Ludwig T: Local proteolytic activity in tumor cell invasion and metastasis. Bioessays 27: 1181-1191, 2005.

3. Schirrmacher V: Cancer metastasis: experimental approaches, theoretical concepts, and impacts for treatment strategies. Adv Cancer Res 43: 1-73, 1985.

4. Swiercz R, Keck RW, Skrzypczak-Jankun E, Selman SH and Jankun J: Recombinant PAI-1 inhibits angiogenesis and reduces size of LNCaP prostate cancer xenografts in SCID mice. Oncol Rep 8: 463-470, 2001.

5. Vihinen P, Ala-aho R and Kahari VM: Matrix metalloproteinases as therapeutic targets in cancer. Curr Cancer Drug Targets 5: 203-220, 2005.

6. Arlen PM, Gulley JL, Parker C, et al: A randomized phase II study of concurrent docetaxel plus vaccine versus vaccine alone in metastatic androgen-independent prostate cancer. Clin Cancer Res 12: 1260-1269, 2006.

7. Lara PN Jr, Stadler WM, Longmate J, et al: A randomized phase II trial of the matrix metalloproteinase inhibitor BMS275291 in hormone-refractory prostate cancer patients with bone metastases. Clin Cancer Res 12: 1556-1563, 2006.

8. Molina JR, Reid JM, Erlichman C, et al: A phase I and pharmacokinetic study of the selective, non-peptidic inhibitor of matrix metalloproteinase BAY 12-9566 in combination with etoposide and carboplatin. Anticancer Drugs 16: 997-1002, 2005.

9. Chorostowska-Wynimko J, Swiercz R, Skrzypczak-Jankun E, Wojtowicz A, Selman SH and Jankun J: A novel form of the plasminogen activator inhibitor created by cysteine mutations extends its half-life: relevance to cancer and angiogenesis. Mol Cancer Ther 2: 19-28, 2003.
10. Jedinak A and Maliar T: Inhibitors of proteases as anticancer drugs. Neoplasma 52: 185-192, 2005.

11. Puli S, Lai JC and Bhushan A: Inhibition of matrix degrading enzymes and invasion in human glioblastoma (U87MG) cells by isoflavones. J Neurooncol 79: 135-142, 2006.

12. Menashi S, Lu H, Soria C and Legrand Y: Endothelial cell proteases: physiological role and regulation. Baillieres Clin Haematol 6: 559-576, 1993.

13. Inoue $M$, Sawada $T$, Uchima $Y$, et al: Plasminogen activator inhibitor-1 (PAI-1) gene transfection inhibits the liver metastasis of pancreatic cancer by preventing angiogenesis. Oncol Rep 14: 1445-1451, 2005.

14. Van Hinsbergh VW, Engelse MA and Quax PH: Pericellular proteases in angiogenesis and vasculogenesis. Arterioscler Thromb Vasc Biol 26: 716-728, 2006.

15. Lawrence DA, Strandberg L, Ericson J and Ny T: Structurefunction studies of the SERPIN plasminogen activator inhibitor type 1. Analysis of chimeric strained loop mutants. J Biol Chem 265: 20293-20301, 1990.

16. Tucker HM, Mottonen J, Goldsmith EJ and Gerard RD: Engineering of plasminogen activator inhibitor- 1 to reduce the rate of latency transition. Nat Struct Biol 2: 442-445, 1995.

17. Usher PA, Thomsen OF, Iversen P, et al: Expression of urokinase plasminogen activator, its receptor and type- 1 inhibitor in malignant and benign prostate tissue. Int J Cancer 113: 870-880, 2005.

18. Andreasen PA, Egelund R and Petersen HH: The plasminogen activation system in tumor growth, invasion, and metastasis. Cell Mol Life Sci 57: 25-40, 2000.

19. Dellas C and Loskutoff DJ: Historical analysis of PAI-1 from its discovery to its potential role in cell motility and disease. Thromb Haemost 93: 631-640, 2005.

20. Ehrlich HJ, Gebbink RK, Keijer J, Linders M, Preissner KT and Pannekoek H: Alteration of serpin specificity by a protein cofactor. Vitronectin endows plasminogen activator inhibitor 1 with thrombin inhibitory properties. J Biol Chem 265: 13029-13035, 1990.

21. Lambers JW, Cammenga M, Konig BW, Mertens K, Pannekoek H and van Mourik JA: Activation of human endothelial cell-type plasminogen activator inhibitor (PAI-1) by negatively charged phospholipids. J Biol Chem 262: 17492-17496, 1987.

22. Bergstralh DT, Conti BJ, Moore CB, Brickey WJ, Taxman DJ and Ting JP: Global functional analysis of nucleophosmin in Taxol response, cancer, chromatin regulation, and ribosomal DNA transcription. Exp Cell Res 313: 65-76, 2007.

23. Bommer UA and Thiele BJ: The translationally controlled tumour protein (TCTP). Int J Biochem Cell Biol 36: 379-385, 2004.

24. De Lano WL: The PyMOL molecular graphics system. PyMOL v. 0.98., 2005

25. Guex N and Peitsch MC: SWISS-MODEL and the SwissPdbViewer: an environment for comparative protein modeling. Electrophoresis 18: 2714-2723, 1997.

26. Cohen GE: ALIGN: a program to superimpose protein coordinates, accounting for insertions and deletions. J Appl Crystallograph 30: 1160-1161, 1997.

27. Amagata T, Whitman S, Johnson TA, et al: Exploring spongederived terpenoids for their potency and selectivity against 12human, 15-human, and 15-soybean lipoxygenases. J Nat Prod 66: 230-235, 2003 .

28. Bradford MM: A rapid and sensitive method for the quantitation of microgram quantities of protein utilizing the principle of protein-dye binding. Anal Biochem 72: 248-254, 1976.

29. Basrur V, Yang F, Kushimoto T, et al: Proteomic analysis of early melanosomes: identification of novel melanosomal proteins. J Proteome Res 2: 69-79, 2003.

30. Jankun J, Maher VM and McCormick JJ: Malignant transformation of human fibroblasts correlates with increased activity of receptor-bound plasminogen activator. Cancer Res 51: 1221-1226, 1991.

31. Seiffert D and Loskutoff DJ: Kinetic analysis of the interaction between type 1 plasminogen activator inhibitor and vitronectin and evidence that the bovine inhibitor binds to a thrombinderived amino-terminal fragment of bovine vitronectin. Biochim Biophys Acta 1078: 23-30,1991.

32. Lawrence DA, Olson ST, Palaniappan S and Ginsburg D: Engineering plasminogen activator inhibitor 1 mutants with increased functional stability. Biochemistry 33: 3643-3648, 1994.

33. Jankun J, Specht Z, Szkudlarek M, et al: Plasminogen activator inhibitor-1 is locked in active conformation and polymerizes upon binding ligands neutralizing its activity. Int J Mol Med 17: 437-447, 2006. 
34. Lee $\mathrm{HJ}$ and $\mathrm{Im} \mathrm{H}$ : Purification of recombinant plasminogen activator inhibitor-1 in the active conformation by refolding from inclusion bodies. Protein Expr Purif 31: 99-107, 2003.

35. Hagglof P, Bergstrom F, Wilczynska M, Johansson LB and Ny T: The reactive-center loop of active PAI-1 is folded close to the protein core and can be partially inserted. J Mol Biol 335: 823-832, 2004.

36. Balsara RD, Castellino FJ and Ploplis VA: A novel function of plasminogen activator inhibitor-1 in modulation of the AKT pathway in wild-type and plasminogen activator inhibitor-1deficient endothelial cells. J Biol Chem 281: 22527-22536, 2006.

37. Czekay RP, Aertgeerts K, Curriden SA and Loskutoff DJ: Plasminogen activator inhibitor-1 detaches cells from extracellular matrices by inactivating integrins. J Cell Biol 160: 781-791, 2003.

38. Boncela J, Papiewska I, Fijalkowska I, Walkowiak B and Cierniewski CS: Acute phase protein alpha 1-acid glycoprotein interacts with plasminogen activator inhibitor type 1 and stabilizes its inhibitory activity. J Biol Chem 276: 35305-35311, 2001.
39. Grisendi S, Mecucci C, Falini B and Pandolfi PP: Nucleophosmin and cancer. Nat Rev Cancer 6: 493-505, 2006.

40. Slupianek A, Nieborowska-Skorska M, Hoser G, et al: Role of phosphatidylinositol 3-kinase-Akt pathway in nucleophosmin/ anaplastic lymphoma kinase-mediated lymphomagenesis. Cancer Res 61: 2194-2199, 2001.

41. Ii M, Yamamoto H, Adachi Y, Maruyama Y and Shinomura Y: Role of matrix metalloproteinase-7 (matrilysin) in human cancer invasion, apoptosis, growth, and angiogenesis. Exp Biol Med 231: 20-27, 2006.

42. Tuynder M, Fiucci G, Prieur S, et al: Translationally controlled tumor protein is a target of tumor reversion. Proc Natl Acad Sci USA 101: 15364-15369, 2004.

43. Tuynder M, Susini L, Prieur S, et al: Biological models and genes of tumor reversion: cellular reprogramming through tpt1/TCTP and SIAH-1. Proc Natl Acad Sci USA 99: 14976-14981, 2002.

44. Zhang G, Cai X, Lopez-Guisa JM, Collins SJ and Eddy AA: Mitogenic signaling of urokinase receptor-deficient kidney fibroblasts: actions of an alternative urokinase receptor and LDL receptor-related protein. J Am Soc Nephrol 15: 2090-2102, 2004. 